\title{
قضايا السمنة بين علم الاجتماع والعلوم الأخرى
}

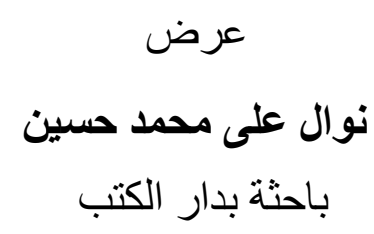

المحترفين ـ بحث الدكتور اه الخاص بها ينطوي على صقل أسلوب الرواية المحوسب لتقييم صورة الجسم في البدناء.

ألكساندرا جونستون : هي أحد كبار

العلماء في قسم التمثيل الغذائي و السمنة المفرطة، وقسم الصحة في معهد البحوث

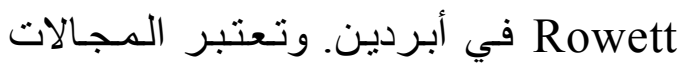

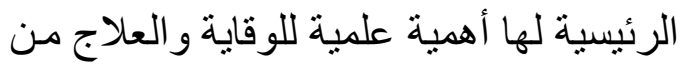

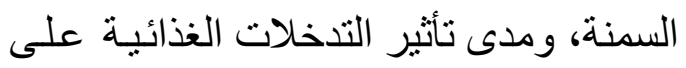
مؤشرات ميزان الطاقة، وتكوين الجسم، و التمثيل الغذائي والصحة. وقد تم عمل
قضايا السمنة بين علم الاجتمـاع والعلوم الأخرى / تحرير جينا تثيليا ، ألكساندرا والاجنا

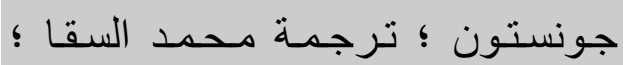

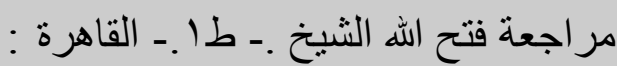

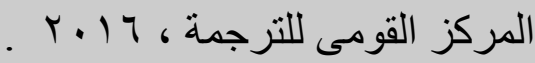

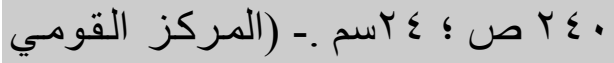

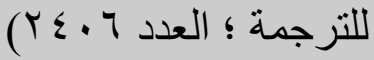
يشتمل على إرجاعات ببليوجر افية.

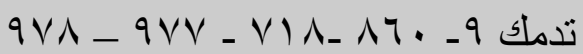

$$
\text { المحررتان فى سطور : }
$$

جينا تتيليا : هي اختصـاصي معتمد للحميات ومحاضر فى جامعة روبرت غوردون، أبردين. هي القائد لدورة ماجستير في التغذية الرياضية. وتكمن الاهتمامـات البحثية لجينا في مجالات السمنة (علم النفس ولنس الانس المرضى و علم الاجتماع للحالة)، و التغذية التهنة الرياضيـة وتكوين الجسم. بـاعتبـارهـا

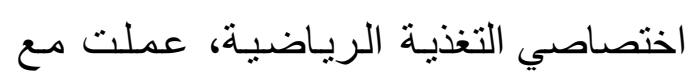

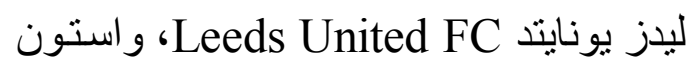
فيلا Aston Villa FC ، ومع الرياضينين 
الاقتصادي العالمي، و إعادة تشكيل أسلوب الحياة مع التغير ات بشكل در اماتيكي، ومؤلم مثل جراحات التجميل فهل سيؤثر الركود الاقتصادي لدينا فى محيط الخطر المنز ايد

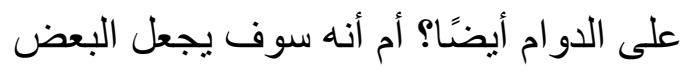
منا فى نهاية المطاف يتقلص إلى حلم ارتداء

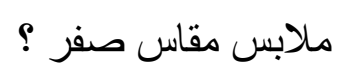

سيحاول - بطريقة منهجيـة - توضيح جوانب مدـا تمـ الإشـارة إلبه على أنـه

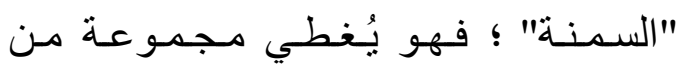

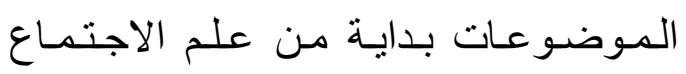
ومرورًا بالطب ووصولاً إلى التكنولوجيا. هذا ليس للخبير المتخصص بدرجـة عـالية، بل هو يظهر التتوع في أساليب تناول ظاهرة السمنة. الموضوع الأول : شكل الإنـاث في وسـائل الإعلام : صورة الجسم والبـانـة، دـ سـارة

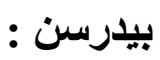

تستكثنف سارة بيدرسن موقفًا متناقضًا للسمنة. إنها تحقق في كيفية أن إثـارة وسـائل الإعلام بـ "الرشاقة المثالية" ووصمة العـار

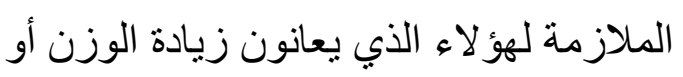

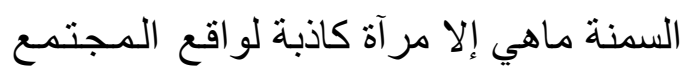
الغربي. وهل هنـاك أي ترابط بين وسـائل الإعلام و التصور ات الخاصة بصورة الجسم هن و السمنة ؟ هل تغير منظورنـا مـع مرور
أبحاث أكثر حداثة بشأن تنظيم الثـهية مـع الحمية ذات نسبة عالية من البروتين وكيفية تحسين حساسية الأنسولين عن طريق تغيبر تركيبة النظام الغذائي . المترجم فى سطور :

محمد السقا : تخرج من كلية الآداب قسم

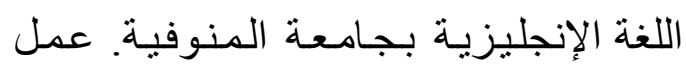

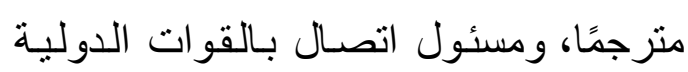

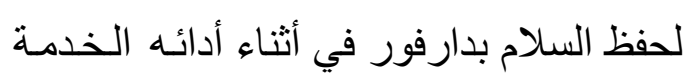

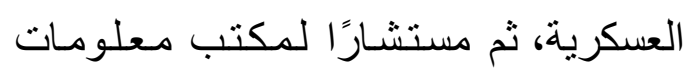

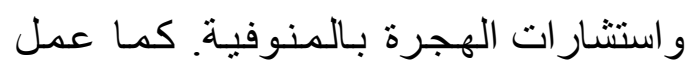

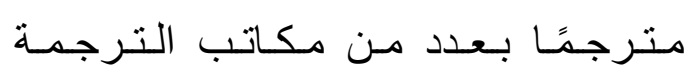

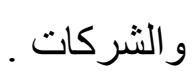
مقدمة : لم تكن البدانة موضو عـا بعيدًا على الإطلاق عن العناوين الرئيسية في الصحافة؛

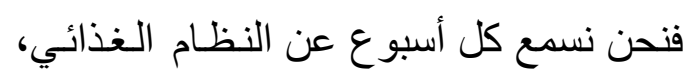
فهناك أحد المشـاهير الذي زاد وزنـه، أو فئون

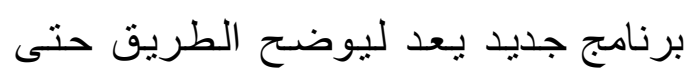

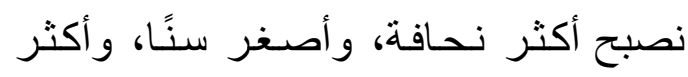
جاذبية، فى "نسخة جديدة" من أنفسنا، وفي مجتمع استهلاكي مهووس بصورة الجسم و النحافة، وصلت مستويات البدانة إلى أعلى لى فئى مستوى على الإطلاق. ومع المجتمـع فى ولى الوقت الر اهن فى ظل "نمط البقاء على قيد الإطى الحياة"، وفى محاولة مكافحة آثار الانهـيـار 
الموضوع الثاني : المحددات للبدانة، لـ مات كيفورثراب :

يأخذ مات كيفورتر اب فى عين الاعتبـار

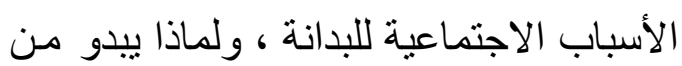
يعيشون في تللك الدرجات الدنيا من المجتمع الدع أكثر عرضة للبدانة ؛ وهو يقول إن هذا ليس هيس مجرد نتيجة الاختلاف فى نمط الغذاء، ولكنه ينتج أيضًا لاختلاف أنماط العمل في مجتمـع عالمي متحرر .

تعتبر السمنة ظاهرة معقدة ؛ إذ تتطلب

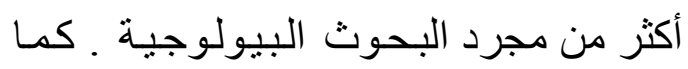
يجب النظر في مستويـات البدانة ضــن سياقاتها التاريخية و الثقافية ، و لاسيمـا مـع المجتمعات و الفترات الزمنيـة التي تهيهى الظروف الموسعة داخل ضـمن مستويـات وزن الجسم التي تحدث للسكان . في بعض الأوقات و الأمـاكن المحددة، تكون التركيبة السكانية الاجتمـاعية لـلأفر اد ذات نأثير مهم على أنمـاط وزن الجسم.

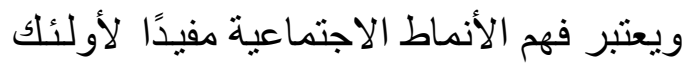
الذين يتعـاملـون مـع الوزن في أدوارهم المهنية. إن تقييم ودر اسة العو امل الاجتماعية بساعد على تأسيس المخاطر الاجتمـاعيـة للسمنة على الأفراد أو السكان. وحتى الآن لم يتم تنفيذ أي بحث في مجال علم اجتمـاع السمنة، وفى الوقت الراهن نشمل النتائج
الزمن ؟ وكيف تقوم وسائل الإعلام بتشكيل

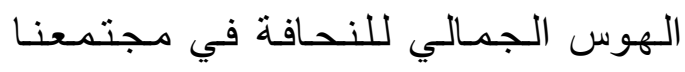
الاستهلاكي لتعزيز صورة الجسد الزائفة و غير القابلة للتحقيق ؟. و هل صحيح أن وسائل الإعلام يمكن أن تؤثر في مواقف النـاس نـحو أجسادهم ؟ المثال الأكثر در اماتيكية من هذا القبيل حدث على جزيرة فيجي في حقبة التسعينيات ؛ ففي عام 990 (م وصل التليفزيون الأمريكى إلى هي الجزيرة، وقبل هذا الوقت كانت تقاليد أهل الجزيرة تقدير أجساد النساء الكبيرة على أنها تتمتع بتنـاول الغذاء الكثنير بدون أيـة

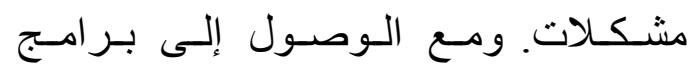
التليفزيون الأمريكي مثل برنسامج بيفرلي هيلز، و الذي عرف الجزيرة على عملية اتباع النظام الغذائي واضطر ابـات الأكل في

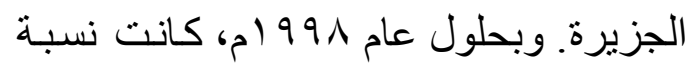
1\% من النساء و الفتيات في فيجسى يقمن

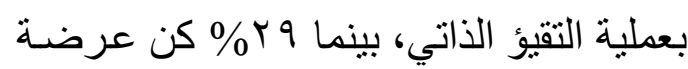
لخطر تطور اضطر ابات الأكل، واتبع 79\%

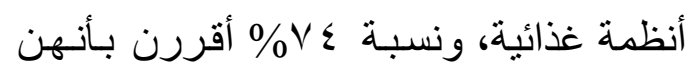
بأنهن "سمينات جدًا". ولم يتغير أي شىء ؤيه آخر على الجزيرة بغض النظر عن الوصول

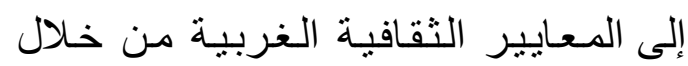
التليفزيون . 
مختلف الأفراد والتخصصـات التى تقترب من الموضوع بطرق مختلفة، ومع هذا الفهم

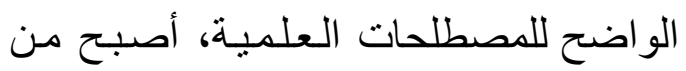
الضرورى فهم ما يدركه الثخص العـادي

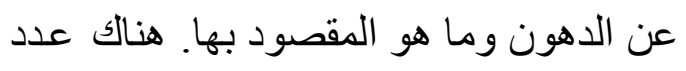
من الأفراد المعنيِين لا يحبون أثكال

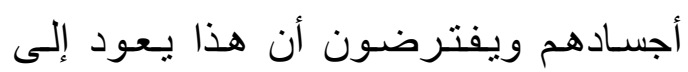

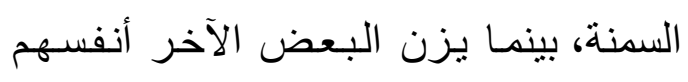
يو ميًا، ويقومون بالمبالغة في تفسير التقلبـات لترن الطبيعية في أجسادهم. إن ما يقصده معظم

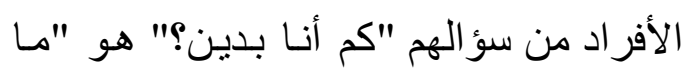
نسبة الدهون في جسمي؟" ولكن السؤال يتطلب المقارنة من أجل توصيل المعنى ـ فقد يكون هذا هو رأي أحد أفراد الأسرة أو جئي

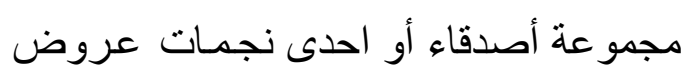
الأزياء أو حتى قياس تكوين الجسم فى أحد بر امج إدارة الوزن و إذا كان ذلك دقيقًا فمن فئن المهم أن نرى حدود النسبـة المئويـة لـه. بالنظر إلى رجل يبلغ وزنه ، 1 كجم ، ونسبة

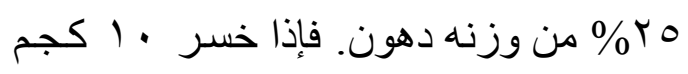
(بالتساوي ما بين الأنسجة الرخوة الخالية من وزن الدهون و الأنسجة الدهنبـة)، فستكون نسبـة

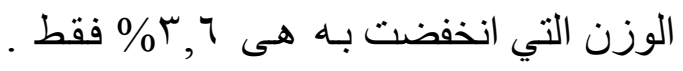
وبتعبير ات مطلقة، فقد انخفضت كتلة الدهون بنسبة ه كجم. و هذا يقدم بعدًا آخر لتقدير كتلة

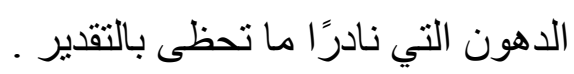
إن تكوين الوزن المفقود أو المكتسب هو
كميات هائلة متفرقة من المعرفة دون أسس

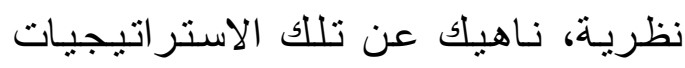
الواضحة عن الكيفية التى يمكن بـها تطبيق المعرفة السطحية الغامضة لتحقيق أهداف لون لهن لهن السياسة العامة .

عندما يقرر المهنيون إما التعامل مع وزن

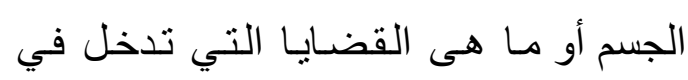

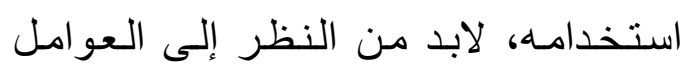

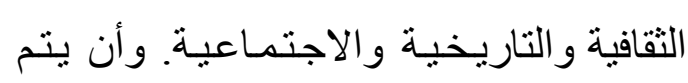

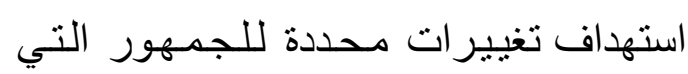
تتطلب أيضًا الأنماط الاجتماعية لوزن الجسم ليتم الاهتمام بها . ليطمات الموضوع الثالث : تقييم السمنة لـ آرثز دـ. ستيوارت : منوع يناقش آرثز ستيو ارت مشكلات المنهجية

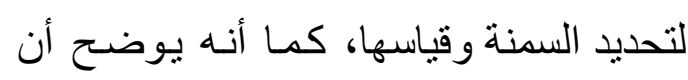

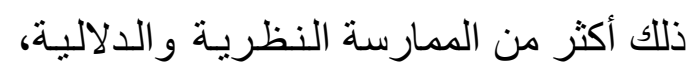
وله نأثير حقيقي في أولئك الذين بعانون

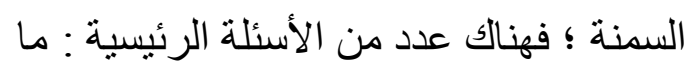
الذى نقصده بالدهون ؟ وكيف نقيس الدهون؟ وكيف يمكن أن نستخدم معرفتنا بتركيب الجسم في الوقت الذي فيه هذه الأسئلة

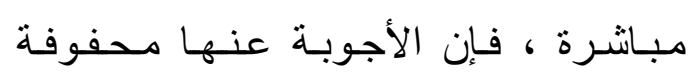
بالمصاعب ، و التى غالبًا مـا يتم التغـاضي عنها. نحن بحاجة إلى فهم كامل "للسمنـة ولى حتى نتجنب الخلط ، و الذى بنتج لامحالة من إن فن 
أجل حياة جديدة أفضل للمصابين بأمر اض وضر الإن

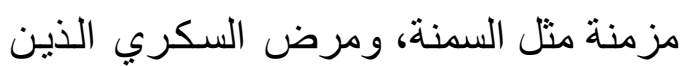
اختاروا استخدامها، كما أن هذه التقنيات التكري النين سوف تشعل الجدل الثقافي والأخلاقي و النفسي حول مدى صحة الخدمة، وكيف ينبغي أن تكون الخدمة / أو الحكومة قادية ولادرة على رصد أنماط الحياة وصحة الأفراد. ويكمن التحدي للمهندسين في اعتماد

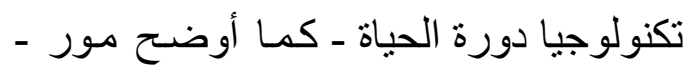

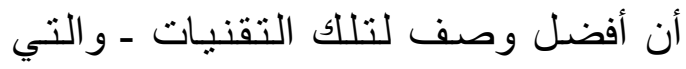

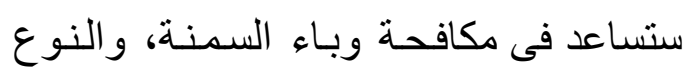
الثناني من مرض السكري - هو أنها "التخرييية" ؛ فالناس يحتاجون إلى استخدام التكنولوجيا لإحداث فرق ـ فإن هناك دائكًا

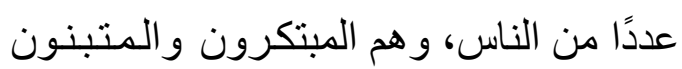

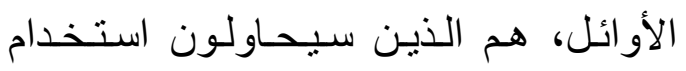
التقنيات الجديدة لمجرد كونها جديدة. وهم

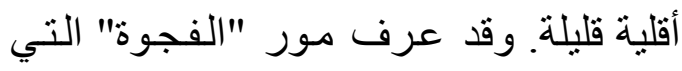
يجب على التكنولوجيا أن تمر بها حتى يتم

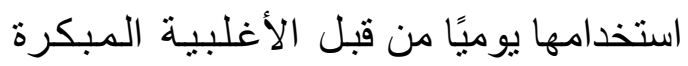

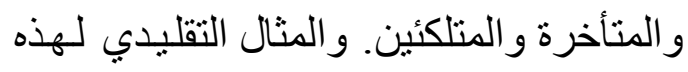
العينة هم هؤلاء الذين لم يستخدموا الحساسب الآلي قط.

ولا يعرفون كيفية استخدامه، إلا أن

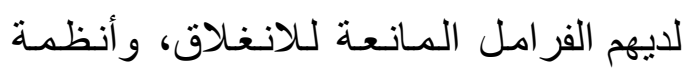

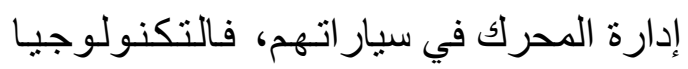
وتعقيداتها، مختقية عن المستخدم، إلا أن له له
دائم مزيج مركب من الأنسجة المختلفة،

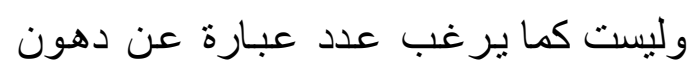
بأكملها مفقودة أو عضلات مكتسبة. بالنسبة لمعظمنا يعتبر مقياس السمنة البديل هو كل ما نحتاج إلى أن نكون واثقين

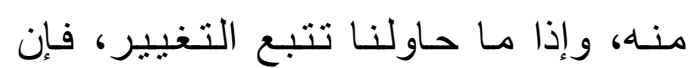
اتجاهات التغير تتحرك صسودًا ورهبوطًا. وجميع الأساليب لديها حدودها، وكثير منها

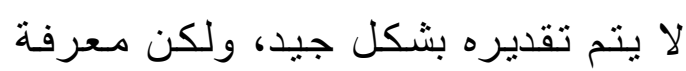

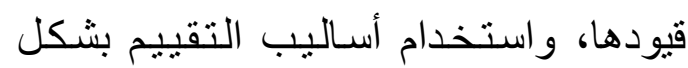
مناسب هو الأساس لكثف قيمتها .

\section{الموضوع الرابع : تكنولوجيا السمنة :} الوقاية والعلاج، دـ ريتشارد بتلر :

يثير ريتشـارد بتلـر إلى أن هنـاك احتمالية في المستقبل القريب أن يتم استخدام أنظمة تحديد المواقع GPS لتعقب فئب إنفاق الطاقة بشكل دقيق، وتحليل استيعـاب الغذاء اليومي بشكل مفصل، و اكتسـاب معلومـات حول أعلى و أقل مستوى لطـاقتنـا، و أيضًا الحصول على رسـائل تذكير على شـاثـة

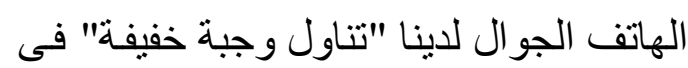
حالة ما إذا كان لدينا "نظام" نفاذ الطاقة . يعمل المهندسون بالفعل على التقنيات التي ستحول مسار الرعاية الصحية للملايين من الناس في العقود القليلة المقبلـة. هذه مئه التقنيات سوف تعمل على خلق احتمالات من 
عثر وما قبله، ولكنه أصبح نـادر الحدوث في الجزء الأخير من القرن العشرين. و أصبح التعاون بشكل أكبر مطلوبًا من قبل من

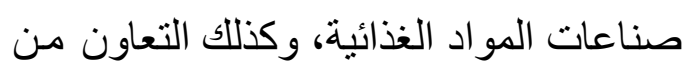
المجتمع ككل، إذا كان وبـاء السمنـة أمرًا ينبخي الحد منه ودفعه في الطريق المعاكس. المـوضـوع السـادس : السـمنـة وفقدان الوزن : الأساطير والواقع، لـ ألكسندرا م. جونستون، سوبيرد : الكأس المقدسة لعلاج السمنـة هي اتبـاع نظام غذائي ـ ولكن النظام الغذائى أمر ليس بالسهل كما يقر معظم الناس الذين مـارسوا

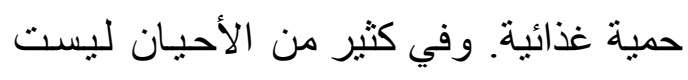

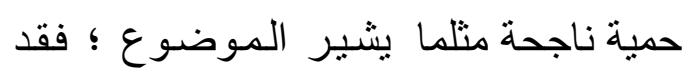
ناقتشت ألكسندرا جونستون وسوبيرد هذا الموضوع ؛ حيث استكثفا الخر افات المتعلقة بالحمية الغذائية فى السؤال الجوهري : هل

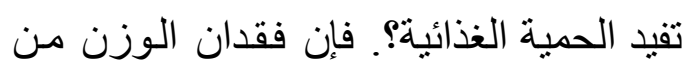
الناحية النظرية هو أمر بسيط ، طـالمـا كان معدل اكتساب الطاقة أقل من إنفاق الطاقـة.

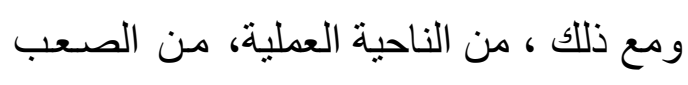
تحقيق ذلك والمحافظلة عليه على المدى دنى الطويل. ويعتبر أحد موضو عات البحوث الخاصة بالبدانة في معهد البحوث Rowett

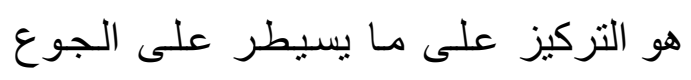

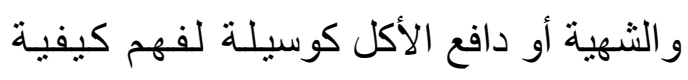
تحسين عملية فقدان الوزن. المشكلة هي أن الن كئن
فيها فو ائد حقيقية.

الموضوع الخـامس : الإنسـان السمين -

نوع جديد من الجنس البشرى : إدارة

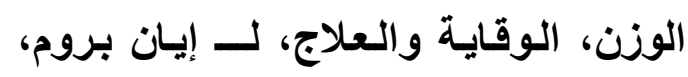
كاترين رولان :

أخذ إيان بروم بعين الاعتبـار التحديات الإكلينيكية في علاج مرضى البدانة ـ وقال

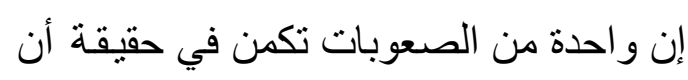

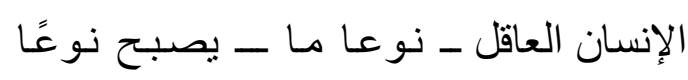
جديدًا، وأن هذا يخلق مضـاعفات لـعلاج

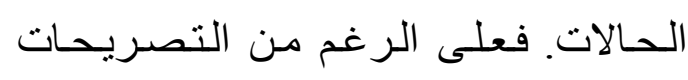

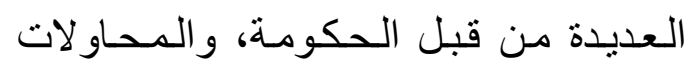
الاستراتيجية لتحقيق السيطرة على وزن السكان، فإن وباء السمنة لا يز ال منتشـرًا.

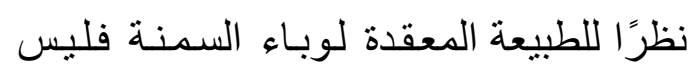

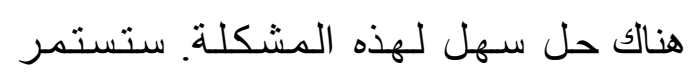

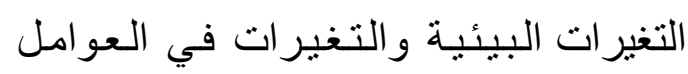

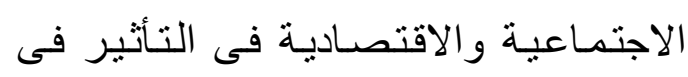
مير اثنا الجيني، وسيكون الإنسـان في حاجـة لتعلم التكيف مع هذه التغير ات إذا كان ينبـي وني

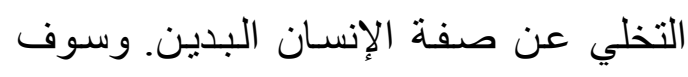
بتطلب ذلك مدخلات رئيسية أسـاسية من جميع فروع الحكومة وليس فقط من وزارة

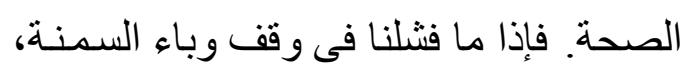
وخصوصًا أنها تؤثر في أطفالنا الآن فسوف فئاء

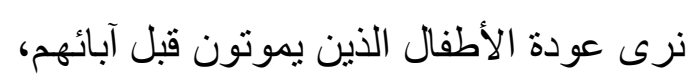

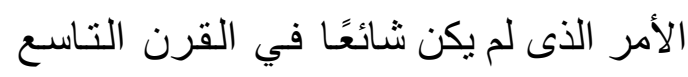


سنوات ووصلت إلى مقاس 17 ـ حافظت على مستوى نشاط بدني متسق من خلال

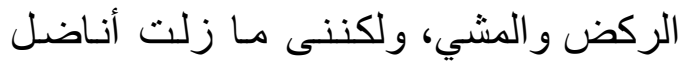
لخفض امتصاص الغذاء للدي، على الرغم من أنني أعرف أن مؤشر كتلة الجسم هو حقًا

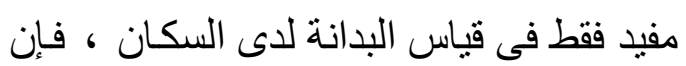

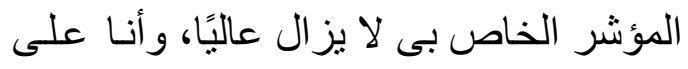

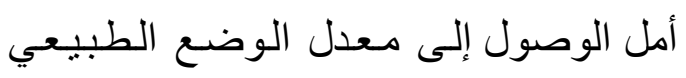

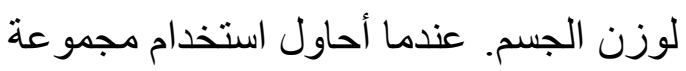
متنو عة من أساليب "تناول الطعام بعقلانيـة" مثل استخدام أطباق أصـغر، وضـــان أن الن نصف مكونات الطبق من الخضروات وليس أكثر من ربعه من البروتين، و الربع الآخر

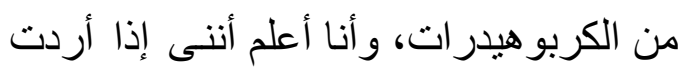

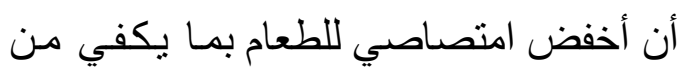
الغذاء لفقد وزن أكثر، فسوف أحتاج إلى عدد

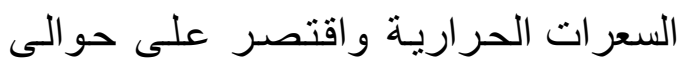
• . . معرًا حراريًا في اليوم الواحد، و على سلى الرغم من أن هذا أقل مدـا هو موصسى بـه ليه

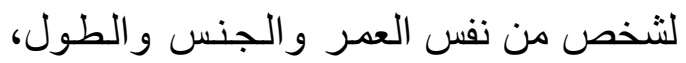
لكن هذا ما تتطلبه جيناتي. بغض النظر عما إذا كنت أستطيع أن أفقد وزنًا أكثر أو لا، فأنا اليوم أكثر صحة بكثير وأكثر ثقة. وأنا أعرف أن نمط حباتى قد حد من خطر تطوبر بعض الأمر اض المزمنة المنتشرة في عائلتي، وأنـا واثقة من أن هذا هو نمط لمط

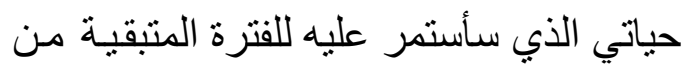

هنالك عو امل خارجية كثيرة (بيئية)، و أخرى داخلية (البيولوجية والنفسية) تؤثر فيما نـأكله ولماذا نأكله، الأمر الذي يجعلنا جميعًا عبارة عن أنظمة معقدة. ينبخي أن يكون الأكل

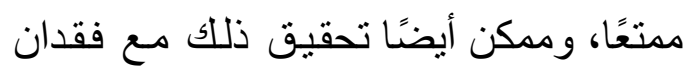
الوزن لتحسين الصحة.

الموضوع السابع : وجهة نظر المريض :

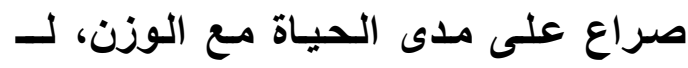

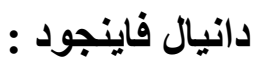

في بعض الأحيان، في أثناء السعي لكثف الأسباب و إيجاد أجوبـة نهائية حول السمنة، من السهل أن ثُنسى الأمور الفرديـة. ولكن البدانة ليست بالأمر الذى يمكن در استه من دون أخذ وجهات نظر المرضهى بـعين الاعتبار . الفهم الذاتى لكيفية الشعور بالسمنـة في نواح كثيرة لا يقل أهمية عن التحليل الموضوعي للظاهرة. وكان غالبًا مـا يقال عن آنا فرويد ــ المحللة النفسيـة وابنة وهية سيجموند فرويد ـ إنها عرفت التعاطف على على أنه : "القدرة على معايشة مو اقف الآخرين ومن ثم الخروج مرة أخرى". سو اء كان هذا

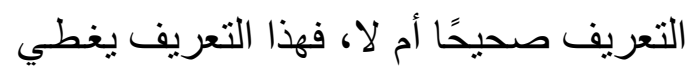
جزءًا مهمًا من التدريب للأطبـاء. ومن ثم فهي مثيرة للاهتمام لقر اعة قصة ديان فينجود من معركتها الخاصة بفقدان الوزن ؛ ففي لهي

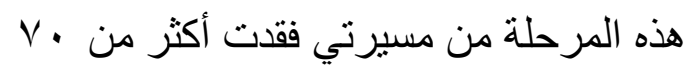

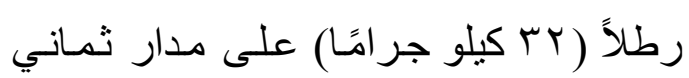


أخصائي التغذية على استخدام مهار ات تقديم حياتي. المشورة، واعتمـاد النهج السلوكي لدعم المرضى في إجراء تغييرات على نمط

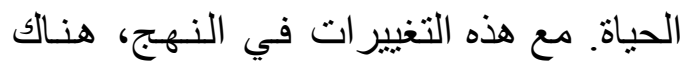
تشديد منزايد في الخدمات الصحية على هده أخصـائيي التغذيـة لتنميـة الوعي الذاتي وفهمهم للآثار المحتملة على المرضى . وينطوي هذا على الإشر اف في مكان العمل، واستخدام السجلات التي تعكس مـاتعلموه

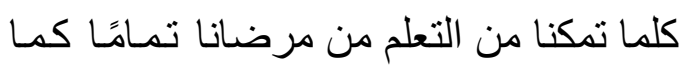
تمكن مرضانا من التعلم منا . الموضوع التـاسع : هل الســمنـة حالة

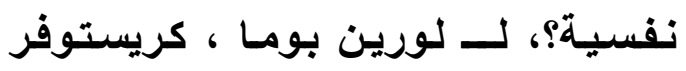
أوتثنر ، ألين جيلبرت :

وهى منـاقثــة السمنـة كحـالة نفسيـة، و المجال الآخر ، الذى يبدو أنه قد تم تجـاهلـه فى الأدبيات و المر اجع. ولكن البدانـة ليست مجرد فيزيولوجية. ليست فقط حول السعرات الحرارية واستهلاك الطاقة، فهي أيضًا تدور حول كيفيـة شعورنـا بأنفسنا وبأجسامنـا. فالسمنة ظاهرة نفسية يمكن التعامل معهـا (جزئيًا) على هذا النحو ـ إن العو امل النفسيـة التي تكون سبيًا أو نتيجة للسمنة تتفاعل مـع تللك العـوامل البيـولوجيـة (الوراثيـة) و المتغير ات البيئيـة التي تحدد فى نهايـة المـوضوع الثامسن : عمل "المـريض" و"الـخـبـيـر" مسعــا فـى إدارة الـوزن، لـ ماريا ماكويج : تقوم اختصاصية التغذية مـاريـا مـاكويج

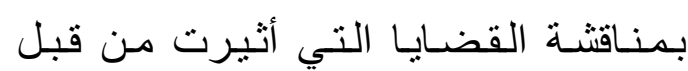
استر اتيجية العلاج فى الوقت الر اهن داخل نظامنا الصحي الوطني وتأثيره في المريض على حد سو اء، و اختصاصي التغذية على أنه

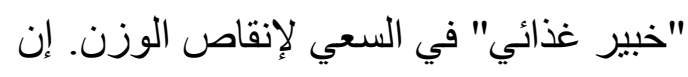
، السمنة مرض مزمن ومنتكس بشكل وبائي

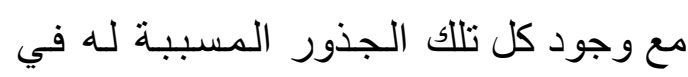
المجتمع ـ وتتخذ إدارة السمنة في الخدمـات الصحية الوطنية ثناثة أبعاد للنهج السلوكي

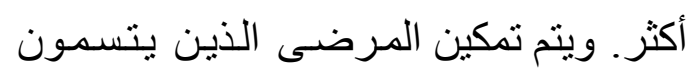

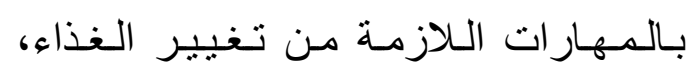
وخيار ات النشاط في بيئتهم الحاليـة. كما يتم

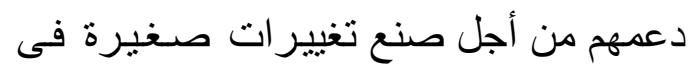
أسلوب حياتهم حتى يحققو اتناقصًا طبيعيًا

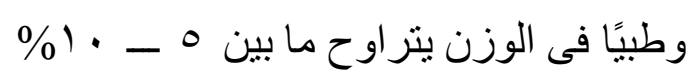

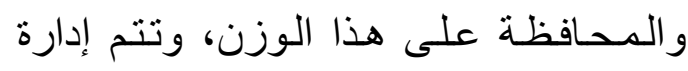
مرضى السمنة من خلال مستويات مختلفة، ولها والتي تكون فيـها نوعيـة العـلاقة بين فين

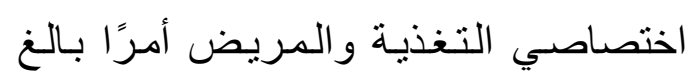

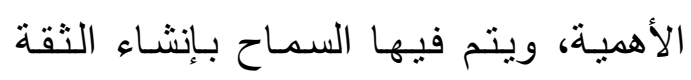
والتفاهم المتبـادل. ويتطور مجـال إدارة

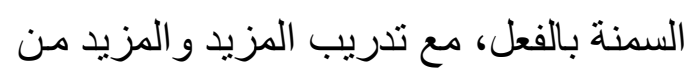


الحال، هنالك مزيد من البحوث التي ينبخي إجر اؤها فى هذ المجال.

ولكننا نأمل أن تفلح مسـاعينـا بـإخبار الجمهور بتلك الأمور التي نوقثت كثيرًا ولكن القليل فقط هو الذى فهم هذه المشكلة.
المطاف من سيعاني السمنة المفرطة. ومـع عدم وجود سبب واحد أو نظريـة شـاملـة

لثرح قضية السمنة، فمن غير المرجح أن ثمة علاجّا بمفرده سيكون فعالاً ــ و السمنة فى حد ذاتها ليست حالة نفسية فى المقام الأول، ولكنها ترتبط أكثر بالأمر اض النفسية عندما يعاني الثخص اضطر ابـات الأكل الثره أو متلازمة الأكل الليلي. وسيتم الاعتر اف بها على نـحو أفضل فى الدليل التشخيصـي والإحصائي للاضطر ابات العقليـة و الذي يجب أن يوفر قوة دافعـة جديدة لعلاجـات جديدة. ونظرًا إلى أن السمنـة ليست مـرد نتيجة لعدم كفاية الإز ادة ، فإن التمييز ضـ ضـ الأفر اد البدناء غير منصف أبدًا. يجب أن تكون هنالك بر امج وقايـة و عـلاج ذات أبعـاد أكثر تعددية لمكافحة وباء السمنة .

وأخيرًا : هذا الكتاب لايتوجهه للخبير المتخصص، بل إنه مصمم للقارىء العـادي الذي يريد الوصول إلى معلومات معمقة عن مشكلة السمنة ؛ فالكتاب يغطى كثيرًا من ين

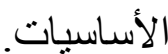

ولن يـهنم جمـيع القراء بـجميـع

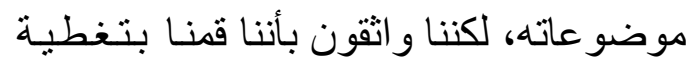
جميع الجوانب الثـاملـة للبدانـة. وبطبيعـة 